\title{
An approach to promote social and communication behaviors in children with Autism Spectrum Disorders: Robot based intervention
}

\author{
Sandra Costa, Filomena Soares, Cristina Santos, Manuel J. Ferreira, IEEE Members, Fátima Moreira, \\ Ana Paula Pereira, Fernanda Cunha
}

\begin{abstract}
Most autistic people present some difficulties in developing social behavior, living in their own world. This study has the goal to improve the social life of children with autism with a main focus in promoting their social interaction and communication. It is necessary to call for children's attention and enforce their collaboration, where a robot, LEGO MindStorm, behaves as a mediator/promoter of this interaction. A set of experiments designed to share objects and fulfill simple orders, by the 11 years old autistic child at the time of daily routine work and in-game with the robot, are described. The generalization of the acquired skills by the child in new contexts and environments are also tested. Results are described showing the outcomes of the experiments.
\end{abstract}

\section{INTRODUCTION}

A utistic Spectrum Disorders (ASD) typically manifests itself during the first three years of life and it can be defined as a global development disorder [1]-[3].

On the basis of diagnosis of ASD, which depends on compiling a personal history [4], it is considered three nuclear behavior modifications, as follows: a) Qualitative changes in social interactions, resulting in the pursuit of social isolation, instrumental relationships, absence of an awareness of emotions and feelings, and difficulty in imitating actions or situations with a more representative content; (b) Qualitative changes in verbal and non-verbal communication abilities, namely: changes or absence of oral language; echolalia; an idiosyncratic use of language; and changes in the prosody and in the pragmatic linguistic; c) A reduced, repetitive and stereotypical repertoire of activities and interests [5]. This leads to the requirement for immutability in daily routines, the absorbing interest for one or more stereotypical patterns that are restrictive of their interests and the presence of motor mannerisms [6-8]. In

Manuscript received March 17, 2011. This work was supported in part by the Portuguese Foundation for Science and Technology under the Project Contract FCT RIPD/ADA/109407/2009.

Costa, S., (corresponding author phone: +351253510190; fax: +351253510189; email: scosta@dei.uminho.pt) is with the Industrial Electronics Department, University of Minho, Guimarães, Portugal.

Soares, F. O., Santos C.P. and Ferreira, M.J. are with the Industrial Electronics Department, University of Minho, Guimarães, Portugal.

Pereira, A. P. is with the Institute on Children Studies, University of Minho, Braga, Portugal.

Moreira, F. is with the APPACDM (an association for mental disable people, in Portuguese Associação de Pais e Amigos do Cidadão com Deficiência Mental), Braga, Portugal.

Cunha, F. is with the primary school EB1/JI of Gualtar, Braga, Portugal. these individuals, the process of game development is characterized, in most cases, by an accentuated lack of imagination and interest for effective exploitation of objects.

Through time, specific methodologies have been used on young children with ASD due to an earlier identification of the problem. It is known the evidence that early intensive intervention may result in substantially enhanced outcomes $[9,10]$. Applied behavior analysis (ABA), the TEACCH method, developmental models, speech and language therapy, social skills instruction, occupational therapy and sensory integration therapy are some of the intervention strategies to enhance communication [9,11-14], teach social skills [14-18] and reduce interfering mal adaptive behaviors $[15,19,20]$.

However, new technologies appear as complementary to the existing methods to develop and improve other skills in people with autism. Thorough research [21-23] focuses on the application of robots into the classroom for children with autism, with the main goal of supporting professionals/ therapists and families in the development of the children cognitive capabilities, social interaction and communication skills. Robots seem to work as a key tool able to call for attention of autistic children, and therefore promote their cognitive and social development [24].

The work presented in this paper is part of a larger collaborative project [25-26] between the University of Minho, APPACDM (an association for mentally disabled people) of Braga and the Special Education Unit of Gualtar Primary School in Braga. The project's main aim is to develop a robotic tool able to improve the social life of children/adolescents with autism, in particular to promoting their social interaction and communication. The robot can be used simultaneously as a complement to daily therapy as well as an alternative to the therapist in their rehabilitation tasks. This releases the therapist and enables the children to perform more intensively, and possibly, even at home. The first steps in this project were given in a case study dedicated to adolescents with ASD and mental impairments, where a robot Lego MindStorm with different configurations was used. Carers, therapists and researchers have previously discussed and plan in detail each of the experiments, according to each adolescent characteristics.

The behavioral impact resulting from this study [25, 26], enabled to verify the adequacy of employed this technology to improve the social life of autistic people. 
Following this trend a new research study was now focused on answering the question: 'Can the robot be assumed as promoting stimulus in establishing social interactions with children with ASD?'

To solve this problem, a mobile modular robotic platform was used as a means (a mediator/promoter) to: a) encourage active participation of the autistic child, and b) promote the social interaction between the child and the others, exploring the concept of generalization of acquired skills.

This article is structured as follows. Section I, introduces the research focus of the paper. Section II describes the related work and highlights the main differences regarding the presented work. Section III describes the applied methodology, including the overall setup. Several scenarios were provided, being changed the following variables: the environment where the trail took place, the person with whom the child played with: acquainted or unknown people, and with and without the presence of the robot. Results are presented and discussed in Section IV. The article ends with conclusions and the future steps of the project.

\section{RELATED WORK}

Therapists of emotional, cognitive and physical impairments use different props to support therapeutic processes. For example, a wide range of toys to foster externalization can be found in children's therapists' working rooms. More recently, the use of robotic toys have been explored to facilitate the therapeutic process of children with ASD, with the robot acting as a mediator between the child and the therapist.

Project AURORA (AUtonomous RObotic platform as a Remedial tool for children with Autism) [27] has been working for several years on the use of robotic systems applied to autistic children. This project looked into how autonomous mobile robots could support children to become engaged in different interactions. The authors concluded that 1) the robot is safe for children use/play, 2) the large majority of children are not afraid of the robot, 3) the children are very motivated to interact with the robot, 4) the children are usually more interested in the robot playing in 'interactive' mode compared to the robot showing noninteractive behavior and 5) the children have no problem coping with the robot behaving reactively but are not completely predictable.

The humanoid robot Robota overcomes some limitations of the previous work, offering a larger range of relations, providing new interactions such as mimicking movements of body parts as well as more complex interactions [22].

Thus, Robota is a doll-shaped robot which uses a motion tracking system to copy upwards movements of the left and right arm of the user when the user faces the camera and reacts to touch. Studies with Robota have two targets: 1) to test systematically the reaction of low-functioning children with autism to the different human features of the robot; 2) to evaluate the extent to which low-functioning children with autism are able to distinguish between perceptions being the result of their own actions from perceptions that are the result of the actions of others. To measure the latter, Robota engages the children in simple imitation games, using the legs, arms and head [22].

KASPAR is an autonomous robot in call-and-response games, where its goal is to imitate the human partner's [28]. The human partner plays a rhythm which KASPAR tries to replicate, in a simple form of imitation. Their approach focused on few expressions and few sensors in order to emphasize the most salient human-like cues of the robot, running experiments that systematically study the influence of each of these cues when interacting with people. Interaction with KASPAR is a multimodal embodied interaction where the complexity of communication can be controlled, tailored to the need of the individual child and gradually increased. In conclusion, the researchers show that the use of KASPAR, not only can demonstrate some important interactional competencies, but also show a level of direct engagement and children appear to generalize this behavior at least to the other people in the room.

Keepon is a robot designed to conduct nonverbal interactions with children, to help to elaborate psychological models of the social intelligence development [29]. The goals of this project were (1) to confirm the effectiveness of their minimal design on attentive and emotive exchange with younger children, and (2) to study how the nature of these interactions changed across age, experience with the robot, and group dynamics. Their major claims are that (1) simple robots with minimal expressiveness can smooth natural exchanges of mental states in autistic children; (2) autistic children possess the motivation for this mental exchange; and (3) the major social difficulties that autistic children generally suffer from stem not so much from a lack of this motivation but rather from the difficulty in sifting out socially meaningful information [29].

The work described in IROMEC project (Interactive Robotic Social Mediators as Companions) takes into account play needs of children focusing its educational and therapeutic goals on reducing children's limitations by taking advantage of their strengths. The IROMEC play scenarios cover different goals in five different developmental areas (sensory, communicational and interaction, motor, cognitive and social and emotional). The researchers conclude that IROMEC as a programmable system (defined as play scenarios) can provide several stimuli that can promote the interaction with the child in different ways [30].

In another line of work on this subject, some researchers have been developing techniques to measure and analyze human/robot interaction (HRI), which could be interesting to extend to the robot/child interaction.

Other interesting trend of investigation presents WearCam, a computer based approach to analyze social interaction experiments for the diagnosis of autism spectrum disorders in young children of 6-18 months of age [31].

The authors presented an answer for the automatic 
analysis of videos from a head-mounted wireless camera for the assessment of social interaction measured as the proportion of time a child spends looking at faces. The system was able to detect more than $51 \%$ of the faces appearing in videos from free play in a cluttered environment. The authors justify the low percentage by saying that comparing to state of the art results, these run on data coming from constrained environments. The intense motion of the head, the wireless transmission noise and the sudden brightness and color intensity changes make the analysis of the WearCam videos challenging. One of the major issues of the system is that although mostly all the faces appearing in the video are detected fairly frequently, the detection is not continuous throughout the frames [32].

In another research project, it is investigated how to increase HRI (Human Robot Interaction) to be used in autism intervention by giving the robot the skill to distinguish and answer to the affective states of a child with ASD. In order to achieve this goal, the authors develop affective models through psycho-physiological analysis and investigate the affect sensitivity during the closed-loop interaction between a child with ASD and the robot. The validation of this system is made from a proof-of-concept experiment (i.e., a robot-based basketball game), where the robot learns the personal liking level of each individual. Results demonstrate that the robot automatically predicted individual liking level in real time with $81.1 \%$ precision. The authors affirm that this is the first time that the affective states of children with ASD have been detected via physiology-based affect recognition technique in real time and that the impact of affect sensitive closed-loop interaction between a robot and a child with ASD has been demonstrated [33].

The work presented in this paper refers to a study, which endorses social interaction by autistic children at the time of individual routine work and in-game with the robot. Furthermore, a comprehensive phase is dedicated to the generalization of the acquired skills when modifying the environment, task execution location, and by changing the scenario, playing/interacting with an unknown person.

\section{Methodology}

As mentioned before, the researched question considered in this study is 'Can the robot be assumed as a motivating stimulus in establishing social interactions with children with ASD?' In the following is described the methodology applied to answer this question.

\section{A. Research goal}

After several meetings between the research team and the child therapists, teacher of Special Education and carers, it was established a program of psycho educational intervention, whose main purpose was to promote social interaction (included in the first Category of Childhood Autism Rating Scale (CARS) - Impairment in Human Relationships [34]). Specifically, the objective was to promote the social interaction between adult/child, prospecting the functional goal, which desires sharing objects and fulfilling simple orders, by the autistic child at the time of individual routine work and in-game with the robot. The generalization of the acquired skills by the autistic child in new contexts and environments was also tested.

\section{B. Environment, Participants and Sessions}

The sessions took place at the Primary School of Gualtar in Braga, EB1/JI of Gualtar, in the Special Education Unit Department.

An 11 years old autistic child was chosen as the target group for the experiments (with the previous consent of his parents). He is not able to speak, but he is capable of producing vocalizations. He manifests difficulties in establishing eye contact, in the interaction with pairs and adults and, above all, difficulties in directing and keeping the attention. At the behavioral level, he reacts strongly to changes in daily routine by crying or even showing aggressive manners. He has not made acquisitions of academic skills: reading, writing and arithmetic calculation.

The activity set-up was constituted by: the researcher and the child, the robot, a guide-path and a ball. The bidirectional task assigned to the experiments constituted of throwing a ball by the child in the direction of the robot, upon request from the adult, and vice-versa, the robot sent the ball to the child, upon child verbal request.

All sessions were recorded for further video analysis and the frequency of the experiments was three days a week during one week. A short process of familiarization with the child and a pre-test were previously performed. It was made a re-test and started the generalization phase again during two weeks with four sessions (two days in each week). Next sub-section details the research program defined.

\section{Research Test Program}

The test program was divided into five phases: Familiarization, Pre-test, Practice, Re-Test and Generalization (Table 1).

Table 1 Test Program Research phases

\begin{tabular}{llccc}
\hline \multicolumn{1}{c}{ Phase } & \multicolumn{1}{c}{ Participants } & $\begin{array}{c}\text { Number } \\
\text { of } \\
\text { sessions }\end{array}$ & $\begin{array}{c}\text { Session } \\
\text { Duration }\end{array}$ & Frequency \\
\hline Familiarization & Researcher, Child & 1 & $1 \mathrm{~h}$ & 2 days \\
Pre-Test & $\begin{array}{l}\text { Researcher, Child } \\
\text { and Robot }\end{array}$ & 1 & $0,5 \mathrm{~h}$ & 1 day \\
Practice & $\begin{array}{l}\text { Researcher, Child } \\
\text { and Robot }\end{array}$ & 3 & $10 \mathrm{~min}$ & $\begin{array}{c}3 \text { days } \\
\text { during a } \\
\text { week }\end{array}$ \\
Re-Test & $\begin{array}{l}\text { Researcher, Child } \\
\text { and Robot } \\
\text { Researcher, Child } \\
\text { and Robot }\end{array}$ & 1 & $10 \mathrm{~min}$ & $\begin{array}{c}\text { 1 day } \\
\text { Generalization }\end{array}$ \\
\hline
\end{tabular}

The main goal of the first phase, Familiarization, was to get acquainted to the child and the integration of the 
researcher in his school environment. The researcher monitored the regular teaching activities, in two specified days, from $3 \mathrm{pm}$ to $5 \mathrm{pm}$. During this phase, the researcher also identified the place where the experiments should be performed and where the camera should be placed to record the child movements. It was felt the need to incorporate the familiarization phase because it is necessary a closer relationship with the researcher (in normal context, it already exists between child family members and therapists).

The Pre-test phase was the first test with the child, robot and researcher in the classroom. The objective was to check the first reactions carried out by the child towards the robot; this test is consider the reference to be compared to later test stages, where some variables were then changed. After demonstrating how the experience ran, researcher test model, the child was requested to "ask the robot for the ball". This phase lasted 30 minutes.

The third phase, Practice, ran in the classroom with the child, robot and researcher over three days during a week, during ten minutes sessions. In this phase, the task was introduced in the child daily work. Whenever the child correctly asked for the ball, the robot returned it. The objective was to test if the child had really acquired the competence.

The Re-Test phase was completed in one different day. This phase had the objective to evaluate the consistency of learning that is if the child, after the interruption of the sessions, is able to successfully perform the task, i.e. whether he is able to respond to the initiative of the adult to interact.

Finally, the Generalization phase was performed during two weeks in three sessions. The main goal of this phase was to perform changes of context/models of the experiment, to evaluate child performance and compare to the Pre-Test results. Different environments were tested (classroom and playground), and also different models (with known and unknown game partners). Testing different models allow verifying if the robot worked as a promoter to improve child social interactions. Table 2 summarizes the tested configurations.

Table 2 Test Configuration in the Generalization phase

\begin{tabular}{cccccc}
\hline Session & Robot & Classroom & Playground & $\begin{array}{c}\text { Known } \\
\text { Game } \\
\text { Partners }\end{array}$ & $\begin{array}{c}\text { Unknown } \\
\text { Game } \\
\text { Partners }\end{array}$ \\
\hline 1 & $\mathrm{X}$ & $\mathrm{X}$ & & $\mathrm{X}$ & \\
2 & & $\mathrm{X}$ & $\mathrm{X}$ & $\mathrm{X}$ & $\mathrm{X}$ \\
3 & $\mathrm{X}$ & & $\mathrm{X}$ & & $\mathrm{X}$ \\
4 & $\mathrm{X}$ & & &
\end{tabular}

\section{Activity Criteria Success}

The criteria of success for this experiment were split into four types, as follows:

- First criterion of success: The child throws the ball once in 5 requests;

- Second criterion of success: The child throws the ball twice in 5 requests;
- Third criterion of success: The child throws the ball four times in 5 requests;

- Forth criterion of success: The child throws the ball five times in 5 requests.

\section{E. Indicators}

The results are quantified in term of pre-defined indicators which measured several actions executed by the child, namely:

\section{REACTION TO THE ROBOT}

a. Ignores the robot (Ignores)

b. Displays specific motor manifestations, eg stereotypies (Manifests)

c. Fixes in some detail (Fixes)

II. ACTION (BEHAVIOURS STARTED BY FREE WILL)

a. Prints intentionality to the motor action of manipulation (Manipulates)

b. Answer to request (demand)

III. INVESTMENT IN THE SUBJECT

a. Interaction time around holding/handling the robot.

\section{RESUlTS}

The results obtained in the Pre-Test are considered benchmark values to be compared to the results obtained in the following sessions. Thus, in 30 minutes of total Pre-Test session, the child interacts with the robot $8 \mathrm{~m} 30$ s. In Table 3 , the number of occurrences in each indicator described in sub-section III-E is presented.

Table 3 Pre-Test Results

\begin{tabular}{clc}
\hline \multicolumn{2}{c}{ Indicator } & $\begin{array}{c}\text { Number of } \\
\text { Occurrences }\end{array}$ \\
\hline \multirow{4}{*}{ Reaction } & Fixes & $\mathbf{4}$ \\
& Ignores & $\mathbf{1 1 2}$ \\
& Manifests & $\mathbf{9 3}$ \\
\multirow{3}{*}{ Action } & Manipulates & $\mathbf{5 8}$ \\
& Demand & $\mathbf{2 3}$ \\
\hline
\end{tabular}

As it can be seen in Table 3 , in 30 minutes session, the child fixed the robot only four times, ignoring the robot more than a hundred times. He also showed stereotypies almost 100 times (manifests), manipulating the robot 58 times, 23 of which was asked by the researcher. In order to have a common basis for comparison the number of occurrences in each indicator obtained in the experiences and in the reference level (Pre-Test), the Pre-Test results (30 min session) were re-scaled to the time duration of the sessions, 10 minutes. The number of occurrences in each indicator, reference values, was then approximated to: Fixes - 1, Ignores - 37, Manifests - 31, Manipulates - 19, Demand -7 .

Table 4 presents the results obtained in the Practice phase, where the child performs the same task at request of the researcher. The first session was more dynamic, because the child was engaged $75 \%$ of the time, in the second session a little more than $50 \%$ and finally in the third session a bit 
more than $64 \%$. Even so, it is still well above the time of interaction of the Pre-Test time which lies in $28 \%$. In these three sessions, highlights the large number of times in which the child fixed in the experiment/robot and less the number of stereotypies manifested.

Table 4 Practice Results

\begin{tabular}{llccc}
\hline & Indicator & \multicolumn{3}{c}{ Number of Occurrences } \\
\hline \multirow{3}{*}{ Reaction } & Fixes & 140 & 50 & 69 \\
& Ignores & 71 & 44 & 54 \\
\multirow{3}{*}{ Action } & Manifests & 16 & 36 & 4 \\
\multirow{2}{*}{ Interaction in 10 minutes } & Manipulates & 192 & 75 & 95 \\
& Order & 37 & 37 & 40 \\
\hline
\end{tabular}

In the Re-Test session, after one week of interruption of the sessions, the child was able to successfully answer to the initiative of the adult to interact. He did it 68 times, performing only 15 times stereotypies (Table 5). The number of times that he ignored the robot equaled the lowest value so far obtained in the first three phases, as well in what concerns to the stereotypical behaviour.

Table 5 Re-Test Results

\begin{tabular}{llc}
\hline \multicolumn{2}{c}{ Indicator } & $\begin{array}{c}\text { Number of } \\
\text { Occurrences }\end{array}$ \\
\hline \multirow{3}{*}{ Reaction } & Fixes & 73 \\
& Ignores & 45 \\
& Manifests & 15 \\
Action & Manipulates & 68 \\
Interaction in 10 minutes & Order & $\mathbf{2 9}$ \\
& & $9 \mathrm{~m} 12 \mathrm{~s}$ \\
\hline
\end{tabular}

Finally, in the Generalization phase, as it was described in sub-section III-C, different scenarios were tested: session in playground and in classroom with known and unknown partners. Analyzing Table 6, it can be seen the results concerning the experiments in the playground, with known and unknown game partners. As it is possible to observe, the child manipulated the robot without the need for the researcher demand. With unknown game partners, the child was perfectly able to answer the request and he did it autonomously. The number of stereotypies registered compared to the Pre-Test was not significant and the time of interaction was higher than $75 \%$. The number of times the child ignored the activity was slightly the same of the Pre-Test but it was due to exterior distractions (bus movement).

The last scenario included an unknown game partner in the classroom. Is it important to underline that this session was performed without the robot, exactly to see if the child could generalize the game objective with a human. Thus, he almost did not presented stereotypies in the alltime session, manipulating the robot 50 times, 39 of which asked by the researcher. The interaction time reached almost $100 \%$.
Table 6 Playground Sessions Results

\begin{tabular}{|c|c|c|c|}
\hline \multicolumn{2}{|c|}{ Indicator } & \multicolumn{2}{|c|}{ Number of Occurrences } \\
\hline \multirow[b]{3}{*}{ Reaction } & & $\begin{array}{l}\text { Known } \\
\text { Game } \\
\text { Partners }\end{array}$ & $\begin{array}{c}\text { Unknown } \\
\text { Game Partners }\end{array}$ \\
\hline & Fixes & 80 & 58 \\
\hline & Ignores & 49 & 37 \\
\hline \multirow{3}{*}{ Action } & Manifests & 10 & 20 \\
\hline & Manipulates & 72 & 47 \\
\hline & Interaction in 10 minutes & $\begin{array}{c}1 \\
9 \mathrm{~m} 15 \mathrm{~s}\end{array}$ & $\begin{array}{c}18 \\
7 \mathrm{~m} 52 \mathrm{~s}\end{array}$ \\
\hline \multicolumn{4}{|c|}{ Table 7 Classroom Sessions Results } \\
\hline \multicolumn{2}{|c|}{ Indicator } & \multicolumn{2}{|c|}{ Number of Occurrences } \\
\hline \multirow{4}{*}{ Reaction } & & \multicolumn{2}{|c|}{ Unknown Game Partner } \\
\hline & Fixes & \multicolumn{2}{|c|}{61} \\
\hline & Ignores & \multicolumn{2}{|c|}{39} \\
\hline & Manifests & \multicolumn{2}{|r|}{8} \\
\hline \multirow{2}{*}{ Action } & Manipulates & \multicolumn{2}{|c|}{50} \\
\hline & $\begin{array}{l}\text { Order } \\
\text { minutes }\end{array}$ & \multicolumn{2}{|c|}{$\begin{array}{c}39 \\
9 \mathrm{~m} 23 \mathrm{~s} \\
\end{array}$} \\
\hline
\end{tabular}

\section{CONCLUSIONS}

In this paper, it was described and reported the results of several experiments performed with an eleven years old child with autism. The goal was to improve his social competences, especially to promote his social interaction and communication by using a robotic tool.

The authors were particularly interested in answering the question 'Can the robot be assumed as promoting stimulus in establishing social interactions with children with ASD?'

Thus, a mobile modular robotic platform was employed to encourage the active participation of the autistic child, and promote his social interaction. Carers, therapists and researchers have previously discussed and planned in detail each of the experiences, according to the child characteristics.

The results obtained in all phases compared to the ones from the Pre-Test session and considering that the child manifested difficulties in directing and keeping the attention, point toward a positive response to the initial research question. In fact, the child managed to perform the task in several constraints, despite the weak results in the Pre-Test. The criteria of success previously defined for this experiment, split into four types of success, were achieved in full. Although, when defining the experiences, the therapists doubt the child could successfully accomplish the test, at the end and in spite of being in different environments and with unknown partners, the child managed to interact and play with others and pronounced simple words. It is worth referring that it was the first time the child played, for a long time interval, with the robot and with known and unknown partners.

The work presented in this paper is very important to guide the future work, where special attention will be devoted to better understand the evolution of interaction 
with time and in different conditions/scenarios. Additionally, other experiments will be addressed, trying to involve strong goals of traditional therapies in these robotic experiments. It is also our aim to extend this research to more autistic people.

\section{ACKNOWLEDGMENT}

The authors are grateful to teachers, therapists, students of the primary school EB1/JI of Gualtar, Braga and their parents for their participation in the project. The authors are also grateful to the Portuguese Foundation (FCT) for funding through the R\&D project RIPD/ADA/109407/2009

\section{REFERENCES}

[1] Schopler, E., G. B. Mesibow (Eds), (1987). Neurobiological issues in autism, en Current issues in autism (series). New York: Plenum Press

[2] Giellberg, C. \& M. Coleman (Eds) (1992). The biology of the autistic syndromes, 2nd ed.,Londres: Mackeith

[3] Happé, F. (1994), Introducción al autismo. Trad. María Núñez Bernardos (1998). Madrid:Alianza Editorial, S.A.

[4] Wing, L.M.D. (2001). The Autistic Spectrum- a parents' Guide to Understandig and helping your child. Berkeley, California: Ulysses Press.

[5] First, M., Frances, A., \& Pincus, H. (2002). DSM-IV-TR - Handbook of differential diagnosis. Arlington: American Psychiatric Association

[6] Siegel, B. (2008). O mundo da criança com autismo: compreender e tratar perturbações do espectro do autismo. Porto: Porto Editora.

[7] Rutherford, M. D., McIntosh, D. N. (2007). Rules versus prototype matching: Strategies of perception of emotional facial expressions in the autism spectrum. Journal of autism and Developmental Disorders, $37,187-196$

[8] Conroy, M. A., Boyd, B. A., Asmus, J. M. \& Madera, D. (2007). A functional approach for ameliorating social skills deficits in young children with autism spectrum disorders. Infants \& Young Children, $20,3,242-254$.

[9] National Research Council, Committee on Educational Interventions for Children with Autism.Educating Children With Autism. Lord C, McGee JP, eds. Washington, DC: National Academies Press; 2001

[10] Olley JG. Curriculum and classroom structure. In: Volkmar FR, Paul R, Klin A, Cohen D, eds.Handbook of Autism and Pervasive Developmental Disorders. 3rd ed. Vol II. Hoboken, NJ: John Wiley \& Sons; 2005:863-881

[11] Goldstein H. Communication intervention for children with autism: a review of treatment efficacy. J Autism Dev Disord. 2002;32:373 -396

[12] Koegel LK. Interventions to facilitate communication in autism. $\mathbf{J}$ Autism Dev Disord. 2000;30:383 -391

[13] Marans WD, Rubin E, Laurent A. Addressing social communication skills in individuals with high-functioning autism and Asperger syndrome: critical priorities in educational programming. In: Volkmar FR, Paul R, Klin A, Cohen D, eds. Handbook of Autism and Pervasive Developmental Disorders. 3rd ed. Vol II. Hoboken, NJ: John Wiley \& Sons; 2005:977 -1002

[14] Paul R, Sutherland D. Enhancing early language in children with autism spectrum disorders. In: Volkmar FR, Paul R, Klin A, Cohen D, eds. Handbook of Autism and Pervasive Developmental Disorders. 3rd ed. Vol II. Hoboken, NJ: John Wiley \& Sons; 2005:946 -976

[15] Bregman JD, Zager D, Gerdtz J. Behavioral interventions. In: Volkmar FR, Paul R, Klin A, Cohen D, eds. Handbook of Autism and Pervasive Developmental Disorders. 3rd ed. Vol II. Hoboken NJ: John Wiley \& Sons; 2005:897 -924

[16] Lorimer PA, Simpson RL, Myles BS, et al. The use of social stories as a preventative behavioral intervention in a home setting with a child with autism. J Posit Behav Interv. 2002;4 :53-60
[17] Taylor BA. Teaching peer social skills to children with autism. In Maurice C, Green G, Foxx RM, eds. Making a Difference: Behavioral Intervention for Autism. Austin, TX: Pro-Ed; 2001:83 -96

[18] Weiss MJ, Harris SL. Teaching social skills to people with autism. Behav Modif. 2001;25:785-802

[19] Campbell JM. Efficacy of behavioral interventions for reducing problem behavior in persons with autism: a quantitative synthesis of single-subject research. Res Dev Disabil. 2003;24 :120 -138

[20] Horner RH, Carr EG, Strain PS, Todd AW, Reed HK. Problem behavior interventions for young children with autism: a research synthesis. J Autism Dev Disord. 2002;32:423 -446

[21] Dautenhahn K. (1999), Robots as Social Actors: AURORA and the Case of Autism, Proceedings CT99, The Third International Cognitive Technology Conference, August 1999, San Francisco, USA

[22] Billard, A., Robins, B., Dautenhahn, K. and Nadel, J. Building Robota, a Mini-Humanoid Robot for the Rehabilitation of Children with Autism, the RESNA Assistive Technology Journal, 19 (2006).

[23] Robins, B., Otero, N., Ferrari, E. and Dautenhahn, K. (2007), Eliciting Requirements for a Robotic Toy for Children with Autism - Results from User Panels.' Procs 16th IEEE Int Symp on Robot and Human Interactive Communication (ROMAN2007).

[24] Salter, T., Werry, I., Michaud, F., Going into the wild in child-robot interaction studies: issues in social robotic development, Intel Serv Robotics (2008) 1:93-108

[25] Costa, S., Resende, J., Soares, F., Ferreira, M. J., Santos, C., Moreira, F., Applications of Simple Robots to Encourage Social Receptiveness of Adolescents with Autism, The 31st Annual International IEEE EMBS Conference, Sept. 2-6, 2009, Hilton Minneapolis, MN, USA

[26] Costa, S., Resende, J., Soares, F., Ferreira, M. J., Santos, C., Moreira, F., Promoting interaction amongst autistic adolescents using robots, The 32st Annual International IEEE EMBS Conference, Aug. 31 2010-Sept. 4 2010, Buenos Aires, Argentina

[27] www.aurora-project.com (accessed on March 2011)

[28] Robins, B, Dautenhahn, K, Dickerson, P., (2009) From Isolation to Communication: A Case Study Evaluation of Robot Assisted Play for Children with Autism with a Minimally Expressive Humanoid Robot. Proc. the Second International Conferences on Advances in Computer-Human Interactions, ACHI 09, February 1-7, Cancun, Mexico. Published by IEEE Computer Society Press

[29] Kozima, H, Michalowski, M, Nakagawa, C, (2009), Keepon: A playful robot for research, therapy, and entertainment, International Journal of Social Robotics, Vol. 1, No. 1, January, 2009, pp. 3-18.

[30] Ferrari, E, Robins, E, Dautenhahn, K, (2009), Therapeutic and educational objectives in Robot Assisted Play for children with autism, The 18th IEEE International Symposium on Robot and Human Interactive Communication Toyama, Japan, Sept. 27-Oct. 2 , 2009

[31] Noris, B, Benmachiche, K, Meynet, J, Thiran, J, Billard, A. (2007), Analysis of Head Mounted Wireless Camera Videos for Early Diagnosis of Autism, International Conference on Recognition Systems, Wroclaw (Poland), 2007. In: Computer Recognition Systems, vol. 2, num. 1, 2007, p. 663-670 Berlin: Springer-Verlag, 2007

[32] Piccardi, L, Noris, B, Barbey, O, Billard, A, Schiavone, G, Keller, F, von Hofsten, C. (2007), WearCam: A head mounted wireless camera for monitoring gaze attention and for the diagnosis of developmental disorders in young children, RO-MAN'2007, In Proceedings of the 16th IEEE International Simposium on Robot \& Human Interactive Communication, 2007

[33] Liu, C, Conn, K, Sarkar, N, Stone, W, (2008), Online Affect Detection and Robot Behavior Adaptation for Intervention of Children With Autism, IEEE Transactions on Robotics, Vol. 24, No. 4, August 2008

[34] Schopler, E., Reichler, R., DeVellis, R., Daly, K., Toward objective classification of childhood autism: Childhood Autism Rating Scale (CARS), Journal of Autism and Developmental Disorders, 1980-0301, Springer Netherlands 